\title{
Achieving Competitive Advantage (CA) through Information Infrastructure Capability (IIC): An Empirical Justification
}

\author{
Lew Sook Ling \\ Melaka, Malaysia
}

\begin{abstract}
The goals of most of the organisations are achieving their sustainable competitive advantage (CA) challenges. One of the organizational initiatives is to invest appropriate information infrastructures. However, organisations may face difficulties to select effective information infrastructures in their respective situations to achieve CA from elusive information. This paper is to connect the Information infrastructure capability (IIC) to CA with empirical justification. Hence, IICs are categorised into dynamic capability (D), integrating capability (I), data management capability (DM), security capability (S), utility capability (U) and collaborating capability (C) from past studies. This paper then empirically test the model using a set of survey data collected from 295 MSC Malaysia companies with the aim to analyse IICs in a holistic way. Four capabilities emerge from the factor analysis as IICs: D, I, DM and U. These results show there is an empirical link between IICs which comprises D, I, DM and U with CA. Finally, a clear full chain of variables model connecting IIC to organisational CA is obtained to fill the research lacuna.
\end{abstract}

Keywords: Information infrastructure capability (IIC); competitive advantage (CA); MSC Malaysia

\section{Introduction}

One of the main challenges for Malaysia to become an intelligent nation is the change in the emphasis of economic development from a production-based economy to a knowledgebased one (Chong, 2005, Sidhu, 2006, Taap, 2001). Among the efforts undertaken by Malaysia is the development of Multimedia Super Corridor (MSC) project which was conceptualised in 1996. The project was modelled after Silicon Valley, which would offer the best of first-world knowledge and infrastructure at developing-nation costs (MDeC, 2010a). This is also an initiative designed to help Malaysia leapfrog into an information and knowledge economy by the year 2020 .

With governmental encouragement, the information and communications technology
(ICT) companies have grown tremendously. In 1997, the country had less than 300 ICT companies (Mergawati, 2006). They have now reached 2,382 (MDeC, 2010b). As for the number of MSC companies, there were only 94 in 1997 but numbered 2,497 to date (MDeC, 2008). To be qualified for preferential status of MSC Malaysia, one of the conditions for the companies is that, at all times, at least $15 \%$ of the total numbers of employees (excluding support staff) are knowledge workers. This requirement is in line with the compliance k-economy initiatives (MDeC, 2008).

While the literature on knowledge management (KM) and ICT is still growing, an online search of databases indicates less than ten information infrastructure IIC related publications in Malaysian context to date. Furthermore, none of the publications

Copyright (C) 2011 Lew Sook Ling. This is an open access article distributed under the Creative Commons Attribution License unported 3.0, which permits unrestricted use, distribution, and reproduction in any medium, provided that original work is properly cited. Contact author: Lew Sook Ling. E-mail: sllew@mmu.edu.my 
discusses IIC in the context presented in this paper.

This paper begins by outlining the study background and issues. A review of the appropriate literature in creating the theoretical model is then completed. Next, statistical analysis will be presented from 295 MSC Malaysia companies which were surveyed and the results will be presented. Finally, study implications and concluded remarks will be discussed.

\section{Study Background and Issues}

Despite the fact that positive role of information infrastructure capability (IIC) for an organisational competitive advantage (CA) was generally supported by many scholars through empirical results, (Bhatt et al., 2010, Paul, 2008, Qi et al., 2008, Schwager et al., 2000, Wang et al., 2007) many past researches noted not all ICT investments contributed into productive outputs (Bharadwaj, 2000, Burca et al., 2006, Weill, 1992).

Past researches have largely focused on general conceptual principles of organisational CA and $\mathrm{KM}$ in leading organisations (Benbya et al., 2004; Chong, 2005; Gertjan et al., 1997; Hahn and Subramani, 2000; Holsapple and Joshi, 2002b; Kim, 2001; Ngai and Chan, 2005; Rajiv and Sanjiv, 2005; Sher and Lee, 2004). There is not much intent on the relationships between information infrastructure capability (IIC) and organisational competitive advantage (CA).

Although past research findings indicate IIC played key role of organisational CA, the underlying mechanisms through which CA is achieved are unclear in our knowledge. It is thus difficult for ICT and knowledge managers to plan effective ICT infrastructures for organisational CA despite all the understanding from the literature about what knowledge is and how it is created, organised, stored/maintained, shared and applied. The difficulties arise because an empirical link does not exist between IIC and organisational CA. A clear full chain of variables model connecting IIC to organisational CA is opportune to fill the research lacuna.

For instance, an extended KM assessment framework was proposed by Kim (2001). This extended framework classifies the organisational KM frameworks into four distinct groups, which may provide more realistic approaches to the industry practices. It is just a starting point for more sophisticated organisational KM framework assessment and development. The author also claims there is no perfect framework developed so far. An inevitable limitation of Kim's framework is that it is based on one assumption: a firm is taking one dominant KM approach. However, some companies are engaged in multiple businesses that are heterogeneous in terms of service type and knowledge type used. As such, when a company is taking multiple $\mathrm{KM}$ approaches, the proposed framework may not be applied. Furthermore, Kim's framework is limited to the management consulting industry in the U.S.A and Canada only. Other industries in different countries may show different results.

In 2004, a study on success factors of KM implementation was carried out. The study has addressed the need for theory-based research on the influence of $14 \mathrm{KM}$ factors on the performance of organisations in Singapore. The research has confirmed previous works on the efficacy along with mechanisms to ensure that the KM success factors proposed would increase the organisational performance (Bawany, 2004). However, empirical link between the IIC and performance was not addressed and focused only on selected companies in Singapore only. The findings could not be extracted to the worldwide markets as well as the Malaysian market.

Later, in 2005, potential impacts of ICT-based KM efforts were reiterated by Rajiv and Sanjiv. The researchers highlight the need for 
managers to carefully consider the specific circumstances surrounding their firms in deciding whether or not, and what kind of ICT-based KM efforts are most appropriate at least in terms of how well they would be received in the short term. However, the study may be limited due to their focus on a specific KM effort. They have made simplifying assumption that each announced KM effort concentrates on one of the activities such as knowledge creation, sharing or applying. In fact, a firm may have a number of mechanisms and processes.

In addition, there have been numerous studies about KM and ICT. However, there have been only limited physical numbers of studies about KM and its underlying ICT components specifically in the Malaysian context. Studies that have been done in the Western countries cannot be generalised to the Malaysian context due to differences in cultures and business customs (Bawany, 2004, Chong, 2005). Although there were studies done in Asian countries such as Japan (Nonaka, 1994), Singapore (Bawany, 2004), Taiwan (Sher and Lee, 2004), and Hong Kong (Ngai and Chan, 2005), they also may not be generalised to Malaysian context due to differences in cultures and business customs.

Furthermore, although there have been numerous studies about KM, there are only a few studies to suggest or prove that IIC enhance CA in organisations. There have been only a limited number of surveys done by KM experts and consulting companies (Bawany, 2004, Chong and Choi, 2005). Additionally, these surveys only provide a general guideline to identify the success factors of KM implementation in organisations. In order to truly understand the relationships between IIC and organisational CA, it is indispensable to investigate the underlying components of ICT because no individual IIC can exist without its infrastructure support (Benbya et al., 2004, Kim, 2001, Meek, 1999, Taap, 2001, Tanriverdi, 2001).
As MSC Malaysia companies pioneer the ICT efforts in Malaysia, a study on these companies would provide a guide to other industries on what are the necessary ICT infrastructures that would aid organisational CA. Consequently, this guide would also serve as a reference point for companies and industries intending to apply information infrastructure or with existing KM framework to identify KM technologies and infrastructures which would be useful for organisational CA.

\section{Theoretical Foundation: Concept of Information Infrastructure Capability (IIC)}

Knowledge has more descriptive value based on recent frameworks proposed as in $\mathrm{KM}$ activities. KM activities are supported by information infrastructures and hence KM capabilities are also supported by information infrastructures (Alavi and Leidner, 2001; Benbya et al., 2004; Bloodgood and Salisbury, 2001; Gertjan et al., 1997; Hahn and Subramani, 2000; Holsapple and Joshi, 2002a; Kim, 2001; Nonaka, 1994; Rajiv and Sanjiv, 2005; Sher and Lee, 2004; Tanriverdi, 2001; Wang et al., 2007; Zack, 1999a).

Sher and Lee (1994) proved that information infrastructure facility often resulted in greater information infrastructure capability (IIC). Competitive advantage (CA) resulting from the deployment and use of information infrastructures was investigated among researchers within the IS field (Wade and Hulland, 2004). The primary finding was that organisations that possess inimitable or nonsubstitutable resources often enjoy sustained CA.

In this study, IIC is a group of information infrastructure capability (IIC) which consists of dynamic capability, integrating capability, data management capability, security capability, utility capability and collaborating capability. As described in literature review, 
each capability of the IIC is distinct. But they are highly interrelated .They constrain, facilitate and reinforce each other.

\section{Dynamic Capability}

KM involves distinct but interrelated processes of KM activities. At any point in time, an organisation and its members can be involved in multiple $\mathrm{KM}$ activity chains. As such, KM is a dynamic organisational phenomenon. Organisations need to be highly responsive in an environment of rapid change. Dynamic capability refers to the ability of organisational flexibility with respect to external challenges (Blake, 1998; Debowski, 2006; Hahn and Subramani, 2000; Nonaka, 1994; Paul, 2008; Rajiv and Sanjiv, 2005; Sher and Lee, 2004; Tanriverdi, 2001; Wang et al., 2007).

The core feature of IIC is having dynamic capability between dynamic aspects of organisational KM activities. Organisations need to be flexible and innovative when the timing of market entry and technological change demand highly responsive decisions and when future competition and market structures are difficult to forecast (Sher and Lee, 2004). For instance, in collecting organisational knowledge, easy to use and easy to remember retrieval mechanisms (e.g., search and retrieval commands) are important aspects of an organisational KM strategy while a variety of search and retrieval approaches and tools exist. The challenge in design of organisational knowledge retrieval strategies is providing timely and easy access to knowledge while avoiding a condition of information overload (Alavi and Leidner, 2001, Tiwana, 2002).

Organisations have responded to external changes of demands and needs by modifying their management practices and core business processes (Debowski, 2006). Hence, flexible workforces with dynamic capability are needed to enable rapid adaptation to changing demand and volatile markets.

\section{Integrating Capability}

Integrating capability refers to the ability of "linking individual components and services for the purpose of sharing software, communication, and data resources" (Kim, 2001). Information from different organisational repositories is integrated in a unified view instead of having information spread across many sources within organisation. The data resources include file servers, databases, business systems, groupware systems, document repositories and the web (Benbya et al., 2004). Integrating capability of ICT infrastructure can ensure enterprise wide compatibility among ICT components so that ICT applications can be assessed and used by employees across the organisation (Kim, 2001).

Effective performance and growth in knowledge intensive organisations require integrating and sharing highly distributed knowledge (Christopher, 2006, Zack, 1999b).

From foregoing discussion, ICT components support ICT applications in different levels. ICT applications will have varying degrees of appropriateness for KM activities. There is a variety of ICT components in an organisation in order to support different levels of $\mathrm{KM}$ activities. Hence, it is indispensable to integrate all physical ICT components (such as hardware, software, data and telecommunications) working together as an integrated resource.

\section{Data Management Capability}

Knowledge is based on data and information (Ngai and Chan, 2005, Tiwana, 2000). Data is raw facts that must be stored, grouped, analysed and summarised to have meaning. When data are organised and processed in a meaningful context, they become information. Knowledge consists of data and information that have been organised and processed to give understanding, experience and expertise 
in a specific context (Benbya et al., 2004, Zack, 1999b). The organised and processed knowledge is actually the KM activities. Hence, data management includes creating, storing, sharing and utilising data.

Data management capability includes the capability to manage data. This capability includes database management systems (Kim, 2001), data storing (databases or online repository) (Zack, 1999a), data tracking (Zack, 1999a), data transaction (Alavi and Leidner, 2001, Zack, 1999a), data analysing (Zack, 1999a) and data translating (Zack, 1999a).

\section{Security Capability}

Security is the capability to minimise ICT vulnerability and abuse (Kim, 2001). Security in an organisation that focuses on maintaining knowledge in its original and constructive state (i.e. not losing it or allowing it to become altered or obsolete) and keeping knowledge from unauthorised transfer to other organisations using policies, procedures, technical and legal measures (Bloodgood and Salisbury, 2001, Kim, 2001). The policies, procedures, technical and legal measures include backup, disaster management and recovery planning (Kim, 2001).

\section{Utility Capability}

Utility capability is another basic aspect of IIC. $\mathrm{KM}$ is the basis for the effective utilisation of many important resources (Ngai and Chan, 2005). Utility capability is the basic and common services that every type of ICT infrastructure has. It works like water and electricity in common public sector (Kim, 2001). Organisations need these basic services to perform better in business world (Weil and Broadbent, 1998).

Even though all capabilities are important, in order to support different needs, different KM frameworks will need different capabilities in different degrees (Kim, 2001, Sher and Lee, 2004). Utility capability includes ICT planning, training, education, customer service and support (Kim, 2001).

\section{Collaborating Capability}

Collaborating capability refers to the ability of "linking people so that they can work together". Collaborating capability of ICT infrastructure can ensure mutual efforts by two or more individuals in order to perform task (Kim, 2001).

The rise of suits of collaboration tools over the last couple of years has been substantial (Christopher, 2006). Most of the largest ICT vendors, for example, IBM, have introduced the concept of activity-centric collaboration through Activity Explorer, and MS Office Communicator delivers enhanced collaboration between many of its synchronous communications. Those developments are a welcome improvement to the collaboration technologies and they are expected to see more in the near future (Christopher, 2006).

Collaboration tools are central to organisational competitive advantage. Common collaboration tools include instant messaging, SMS, e-mail, discussion groups, blogs, wikis, bulletin boards, project workspaces, task lists, calendars, document sharing and corporate portals (Benbya et al., 2004, Christopher, 2006, Kim, 2001). For instance, corporate portals can also give organisational participants the ability to create a shared community because they present a natural forum for online collaboration by assembling a set of content and services to which members of a group have special access (Benbya et al., 2004). Decision support systems were developed to enhance collaborative group work between geographically dispersed professionals. Examples of the collaboration tools in the markets are Lotus Notes, Network Delivery Knowledge and Fulcrum Knowledge Network (Meso and Smith, 2000).

While KM environment is dynamic, ICT vendors are developing the tools in this 
dynamic space. In view of globalisation of business, people should be connected regardless of their physical locations.

\section{Theoretical Model}

The extensive review of literature enables the theoretical model to be constructed along with identification of theory, independent variables and dependent variable. This chapter discusses the Organisational Information Processing Theory (OIPT) and also outlines and explains the research hypotheses based on the theoretical and empirical considerations as described in literature review. A new theoretical model is then summarised to illustrate the proposed relationships between all the variables.

\section{Organisational Information Processing Theory (OIPT)}

The Organisational Information Processing Theory (OIPT), developed by Jay Galbraith, identifies three important concepts: information processing needs, information processing capability and the fit between the two to obtain optimal performance. The concern of OIPT includes organisational needs, organisational capability and effectiveness. Organisations need quality information to cope with environmental uncertainty and improve their decision making. Environmental uncertainty stems from the complexity of the environment and dynamism, or from the frequency of changes to various environmental variables (Galbraith, 1974, Premkumar et al., 2005).

Typically, organisations have two strategies to cope with uncertainty and increased information needs:

1) develop buffers to reduce the effect of uncertainty, and

2) implement structural mechanisms and information processing capability to enhance the information flow and thereby reduce uncertainty.

A classic example of the first strategy is building inventory buffers to reduce the effect of uncertainty in demand or supply; another example is adding extra safety buffers in product design due to uncertainty in product working conditions. An example of the second strategy is the redesign of business processes in organisations and implementation of integrated IS that improves information flow and reduces uncertainty within organisational subunits. A similar strategy is creating better information flow between organisations to address the uncertainties in the supply chain (Galbraith, 1974, Premkumar et al., 2005).

With respect to this paper, information infrastructure capability (IIC) is conceived as organisational needs and capabilities which will lead to the organisational competitive advantage (CA). Hence, this paper is based on OIPT.

\section{Independent Variables}

In this study, independent variable is a group of information infrastructure capability (IIC) (Fig 1). The IIC consists of:

1. Dynamic capability,

2. Integrating capability,

3. Data management capability,

4. Security capability,

5. Utility capability, and

6. Collaborating capability.

As described in section 2, each capability of the IIC is distinct. But they are highly interrelated. They constrain, facilitate, and reinforce each other. 


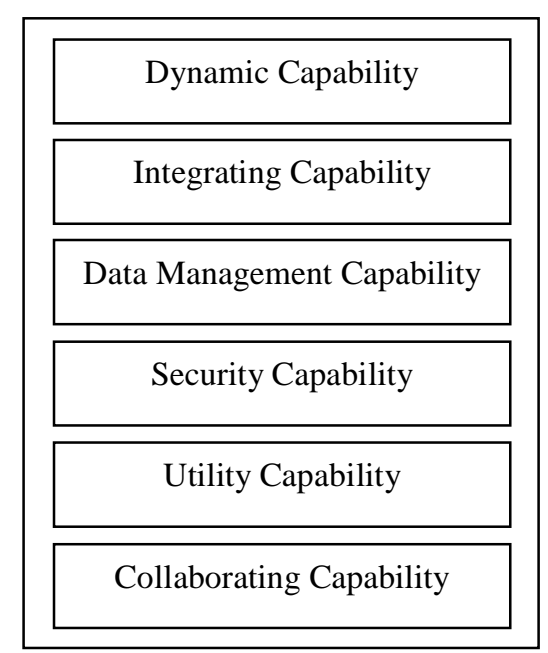

Fig1. Information Infrastructure Capability (IIC)

\section{Dependent Variable}

The dependent variable in this study is organisational competitive advantage (CA). The CA refers to the capability of performing KM activities using IIC (Benbya et al., 2004; Hahn and Subramani, 2000; Holsapple and Joshi, 2002a; Kim, 2001; Nath, 2000; Ngai and Chan, 2005; Sher and Lee, 2004; Tanriverdi, 2001).

In the context of this study, organisational CA refers to the capability of creating, storing, sharing and utilising knowledge using dynamic capability, integrating capability, data management capability, security capability, utility capability, and collaborating capability.

The theoretical model includes two groups of variables. These variables are based on theoretical and empirical considerations as described above. Table 1 summarises the variables: 
Table 1: Summary of Variables

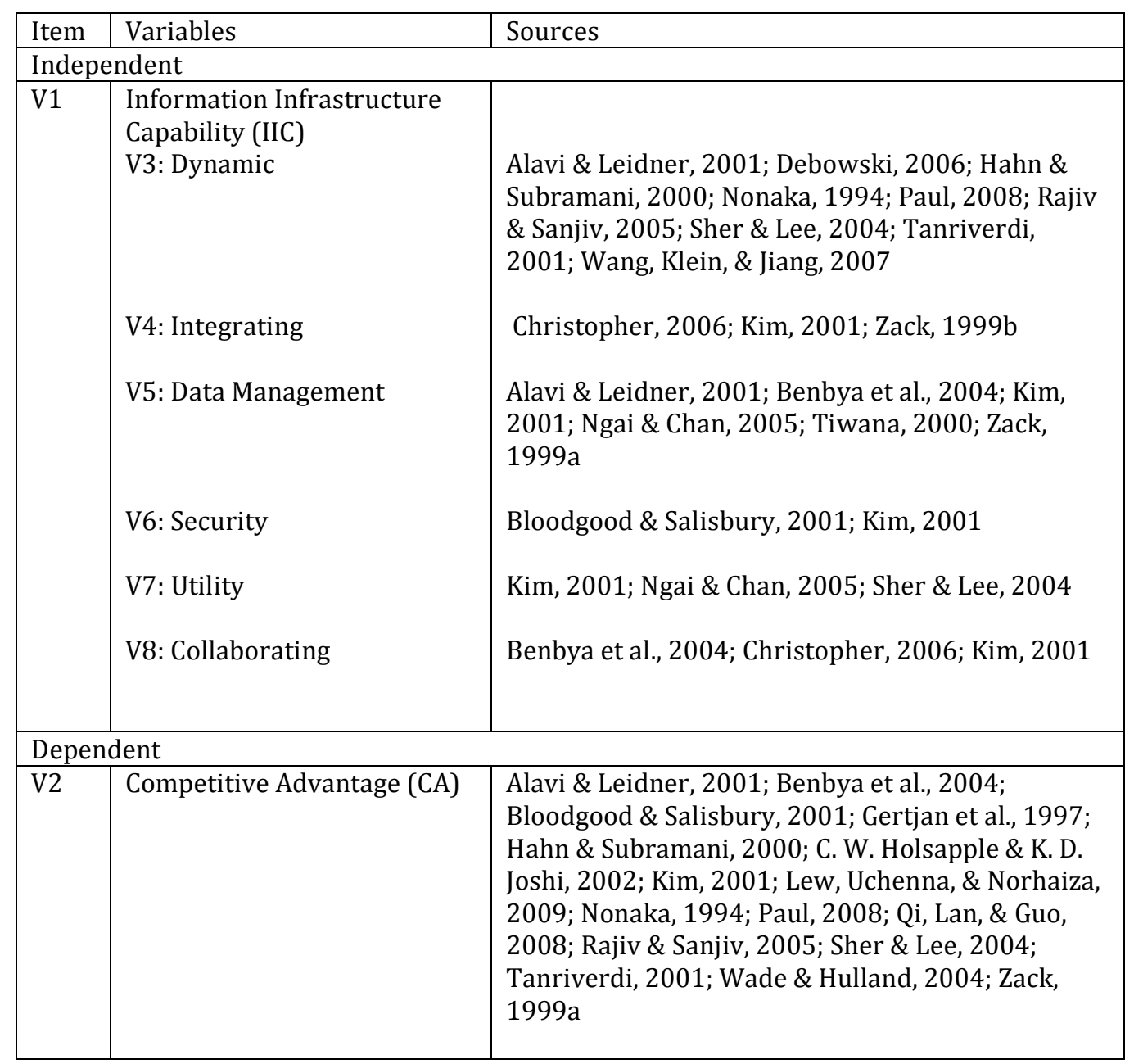

The theoretical model is summarised and presented in Fig 2. The IIC is the independent variable. CA is the dependent variable. The variables are assumed interrelated. They constrain, facilitate, and reinforce each other.
In summary, IIC is conceived as organisational needs and capabilities which will lead to the $\mathrm{CA}$ of $\mathrm{KM}$ implementation. 


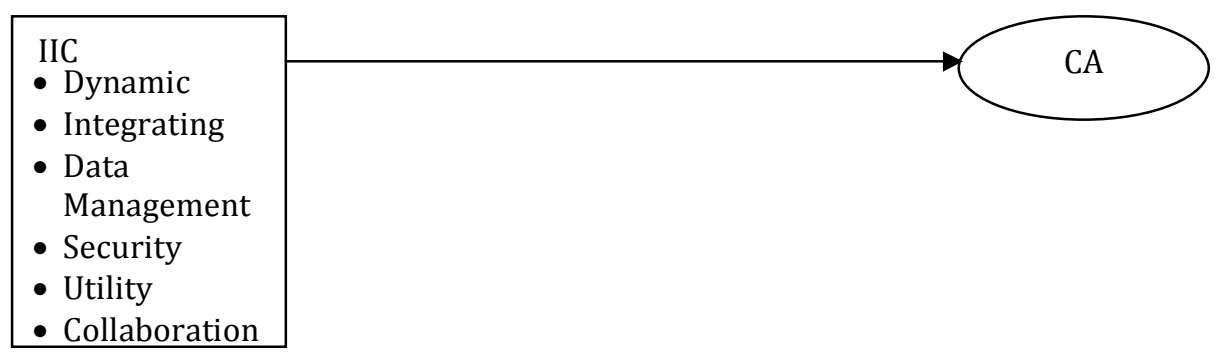

Fig2. Theoretical Model

\section{Model Justification}

600 MSC Malaysia companies were selected from a list obtained from MSC Malaysia website (www.mscmalaysia.com.my) using simple random sampling. The 600 companies were contacted using emails and follow-up phone calls from June to October 2009. There were 302 questionnaires (50.3\%) returned by the respondents.

\section{Descriptive Statistic}

In this study, the final sample of 295 respondents was first analysed using descriptive statistic analysis after list-wise deletion of the cases of respondents with one or more missing values in the questionnaires. This initial analysis provides a feel for the data using and to obtain an insight into the distribution of the respondents' information.

\section{Demographic Profile}

Table 2 shows the demographic profile for the surveyed respondents and organisations. The gender consists of 217 males (73.6\%) and 78 females (26.4). The age survey was categorised by age group and the highest groups are $26-30$ (41.7\%), 31-35 (28.1\%), 36-40 (15.3\%), 21-25 (6.1\%), 41 - 45 (4.7\%) and $46-50$ (4.1\%). Department head forms the largest position group (85.8\%) followed by section head $(13.6 \%)$ and other positions $(0.7 \%)$. Most of the respondents are from IT / EDP department category (34.2\%) and most of them are in the position for 1 - 5 years category $(69.5 \%)$. The qualifications varied between college/diploma to post graduates and higher but the highest percentage is the university (Bachelor Degree) category, with 283 (95.9\%) respondents. The highest group of number of employees is 1 - 50 (25.8\%) followed by 501 and above (25.4\%). 
Table 2: Demographic Profile of MSC Malaysia Managers and Companies

\begin{tabular}{|l|l|l|}
\hline Demographic Profile & Number & Percentage \\
\hline Gender & & \\
Female & 78 & 26.4 \\
Male & 217 & 73.6 \\
\hline Age & & \\
$21-25$ & 18 & \\
$26-30$ & 123 & 6.1 \\
$31-35$ & 83 & 41.7 \\
$36-40$ & 45 & 28.1 \\
$41-45$ & 14 & 15.3 \\
$46-50$ & 12 & 4.7 \\
& & 4.1 \\
\hline Position & & \\
Section Head & 40 & 13.6 \\
Department Head & 253 & 85.8 \\
Others & 2 & 0.7 \\
\hline Department & & \\
IT / EDP & 101 & \\
Quality Control / Assurance & 12 & 34.2 \\
Marketing and Sales & 6 & 4.1 \\
Product Development & 16 & 2.0 \\
Finance & 12 & 5.4 \\
Customer Service & 6 & 4.1 \\
Human Resource & 6 & 2.0 \\
Production & 6 & 2.0 \\
Engineering & 11 & 2.0 \\
R\&D & 54 & \\
Others & 65 & \\
& & \\
\hline
\end{tabular}


Table 2: Demographic Profile of MSC Malaysia Managers and Companies (Continued)

\begin{tabular}{|l|l|l|}
\hline Demographic Profile & Number & Percentage \\
\hline Number of Year(s) in the Position & & \\
$1-5$ & 205 & 69.5 \\
$6-10$ & 88 & 29.8 \\
$11-15$ & 2 & 0.7 \\
\hline Qualification & & \\
College/Diploma & 6 & 2.0 \\
University (Bachelor Degree) & 283 & 95.9 \\
Post graduates and higher & 6 & 2.0 \\
& & \\
\hline Number of Employees & 76 & \\
$1-50$ & 35 & 25.8 \\
$51-100$ & 44 & 11.9 \\
$101-150$ & 18 & 14.9 \\
$151-200$ & 18 & 6.1 \\
$201-250$ & 6 & 6.1 \\
$251-300$ & 11 & 2.0 \\
$301-350$ & 12 & 3.7 \\
$451-500$ & 75 & 4.1 \\
501 and above & & 25.4 \\
\hline
\end{tabular}

\section{Internal Consistency Reliabilities}

The Cronbach's Alpha measures for each variable in this study are summarised in Table 3 below. There are 46 items used for respondents experience and perception of all the seven variables. There are 28-item information infrastructure capability (IIC) scale which is composed of 3-item dynamic (D) scale, 3-item integrity (I) scale, 8-item data management (DM) scale, 3-item security (S) scale, 6-item utility (U) scale and 5 -item collaboration (C) scale. Besides, there is 18-item competitive advantage (CA) scale. The list of items used is presented in Appendix A.

Table 3: Cronbach's Alpha for the Variables

\begin{tabular}{|l|l|l|l|l|l|l|}
\hline \multicolumn{4}{|l|}{ Information Infrastructure Capability (IIC) } & $\begin{array}{l}\text { Competitive Advantage } \\
\text { (CA) }\end{array}$ \\
\cline { 1 - 5 } D & I & DM & S & U & C & 0.91 \\
\hline 0.71 & 0.56 & 0.84 & 0.57 & 0.75 & 0.62 & \\
\hline
\end{tabular}

The internal consistency reliabilities are all above 0.5, which was intended as the minimum cut-off alpha measure. Most of the observed score variance is due to random error if alpha value is less than 0.50 (Kline, 2005, Kline, 2009).

\section{Principal Component Analysis (Pilot Survey)}

Pilot survey was conducted from January to February 2009 using a selected group of 50 middle managers of MSC Malaysia companies. The returned rate was $76 \%$ from them totalling 38 sets. This meets the suggested minimum requirement (Cooper and Schindler, 2006). Exploratory factor analysis (EFA) explores the data and provides the researcher with information about how many factors are needed to best represent the data. With EFA, all measured variables are related to every factor by a factor 
loading estimate. Simple structure results when each measured variable loads highly on one factor and has smaller loadings on other factors (i.e., loadings less than 0.40) (Hair et al., 2010).

The pilot data was first assessed by using EFA by principal component analysis (PCA) with varimax rotation using factor analysis in SPSS version 16.0. All variables were loaded together. The output of 'Rotated Component Matrix,' indicates that all the seven variables accounted for $78.32 \%$. The Kaiser-MeyerOlkin (KMO) Measure of Sampling Adequacy (MSA) exceeds the minimum requirement of 0.50 for overall MSA with Bartlett's Test significant.

Table 4 below shows the output of the rotated component matrix for five variables. The result is congruent with the hypothesised model except security (S) and collaboration (C) variables were deleted.

Table 4: The Rotated Component Matrix (Pilot Study)

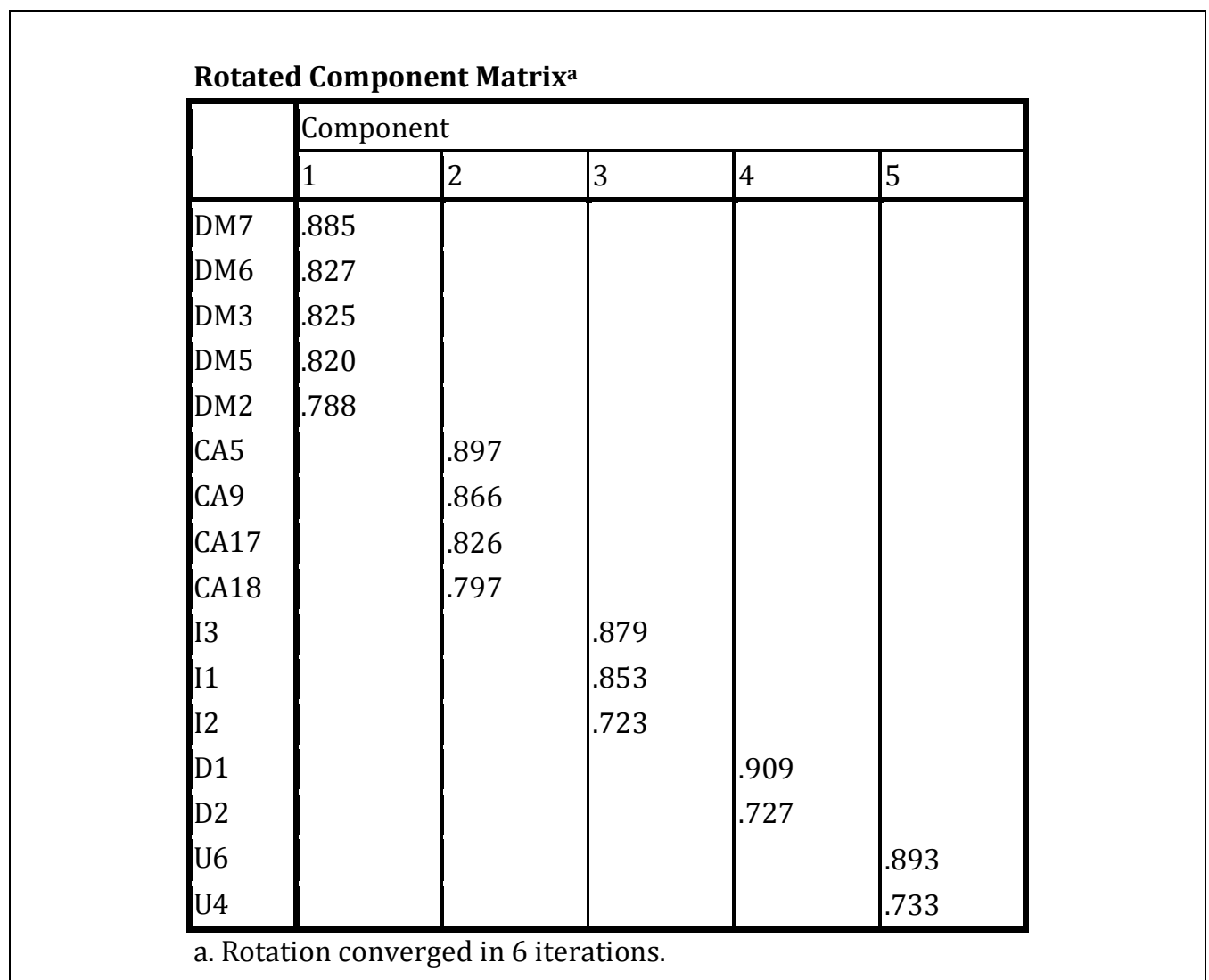

Note: Extraction Method: Principal Component Analysis. Rotation Method: Varimax with Kaiser Normalization.

\section{Principal Component Analysis (Final Survey)}

After reviewing the pilot results, the questionnaire items were refined and reformatted. However, none of the variables are deleted but are kept in view until the whole conceptual model is evaluated. All the variables were again assessed by using factor analysis by PCA with varimax rotation using SPSS version 16.0 in final survey. 
The output of 'Rotated Component Matrix' for the seven variables accounted for 75.33. The Kaiser-Meyer-Olkin (KMO) Measure of Sampling Adequacy (MSA) exceeds the minimum requirement of 0.50 for overall MSA with Bartlett's Test significant. Hence, in this study, pilot and final survey analyses verify that the distributional properties of the data are acceptable for this approach. Table 5 below shows the output of the rotated component matrix of the final survey.

Table 5: The Rotated Component Matrix (Final Survey)

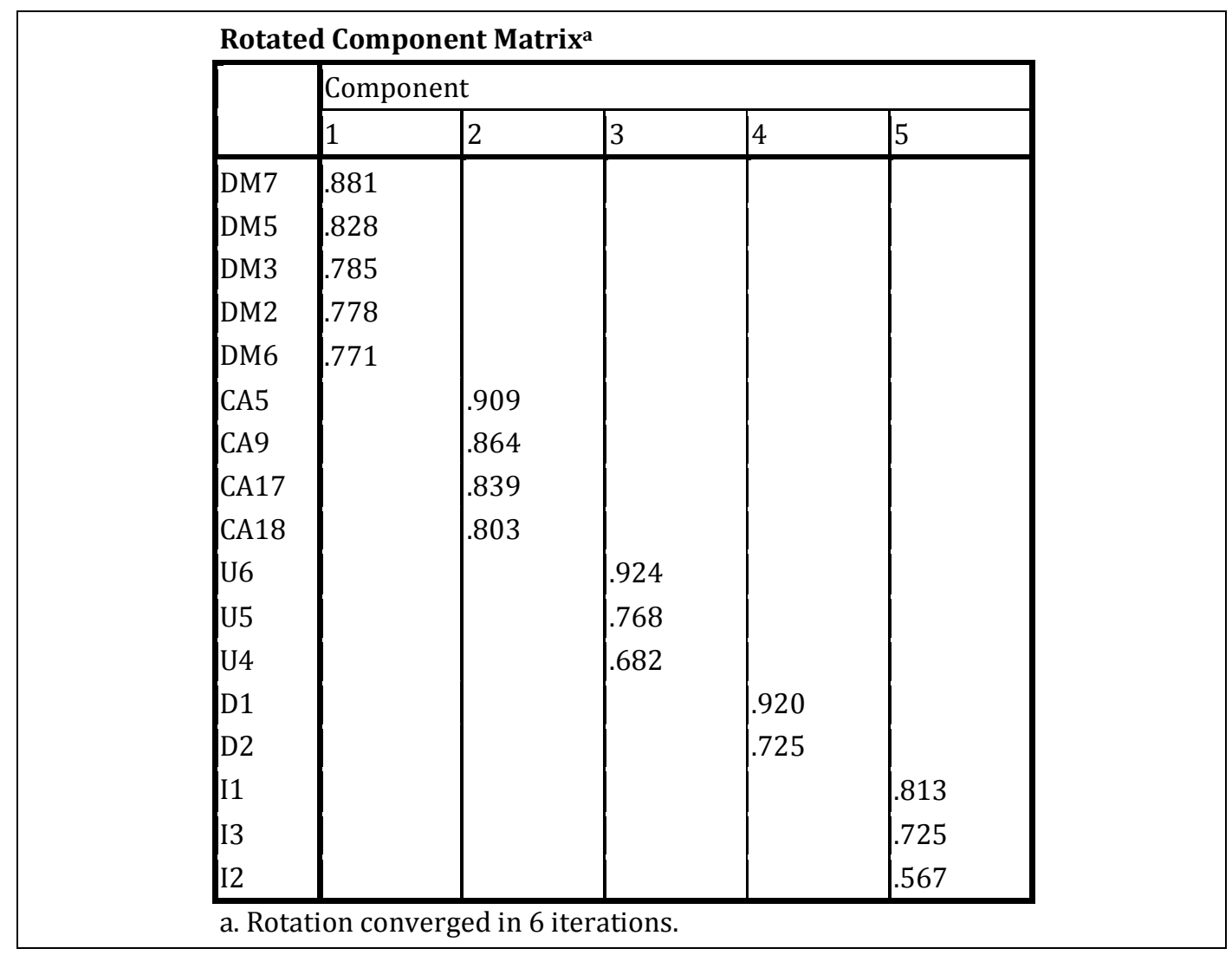

Note: Extraction Method: Principal Component Analysis. Rotation Method: Varimax with Kaiser Normalization.

\section{Research Implications}

The findings of this paper contribute some key ideas and clues to the existing literature on information infrastructure capability (IIC) on organisational competitive advantage (CA), primarily for MSC Malaysia Companies. The current literature and studies on IIC and organisational CA is still scare relative to the existing literature on knowledge management (KM) and ICT. This study represents one of the first few attempts to look into the relationships of IIC and CA in Malaysian context.

While the previous studies demonstrate that there are six capabilities of IIC: dynamic (D), integrating (I), utility (U), collaborating (C), security (S) and data management (DM) capabilities (Alavi and Leidner, 2001; Benbya et al., 2004; Bloodgood and Salisbury, 2001; Christopher, 2006; 
Debowski, 2006; Hahn and Subramani, 2000; Kim, 2001; Nonaka, 1994; Paul, 2008; Rajiv and Sanjiv, 2005; Sher and Lee, 2004; Tanriverdi, 2001; Tiwana, 2000; Wang et al., 2007; Zack, 1999a; Zack, 1999b) to have positive influence on organisational $\mathrm{CA}$; the results from this study reveal there are only four categories of IIC that consist of D, I, U and DM to have positive influence on organisational CA. The $\mathrm{C}$ and $\mathrm{S}$ capabilities were deleted in this study in the process of obtaining the component factors. From the theoretical perspective, the evidence of the theoretical model developed in this study is effective for identifying the categories of IIC achieving organisational CA.

This theoretical model appears to provide the first investigation about the MSC Malaysia companies the relationships of IIC and organisational CA. This is due to, as Malaysia moves into the era of k-economy, MSC Malaysia companies are supposed to pioneer the implementation of information infrastructure, this study on the MSC Malaysia companies would also offer a guideline to companies in other industries on key ICT infrastructure necessary for organisational CA.

\section{Concluded Remarks}

The review of the literatures provides significant evidence on the relationships between organisational competitive advantage (CA) and information infrastructure capability (IIC). However, there is still a lack of understanding of which information infrastructure capability (IIC) is specifically important to consistently contribute to CA. This study specifically investigates which IIC could contribute to organisational CA by determining the relationships to fill up the lacuna. This study findings offer useful information to the MSC Malaysia companies on a clear view of IIC that are needed to effectively implement KM and eventually lead them to future business success. Since MSC Malaysia companies are the pioneer of the implementation of information infrastructure as Malaysia moves into the era of k-economy, it can also be a guideline to companies in other industries on key ICT infrastructure necessary for organisational CA. Academically, it has also set a foundation for the theory, practice and future research areas about the IIC and organisational CA.

\section{Selected References}

Alavi, M. \& Leidner, D. E. (2001). "Review: Knowledge Management and Knowledge Management Systems: Conceptual Foundations and Research Issues," MIS Quarterly, 25, 30.

Bawany, S. (2004). 'Key Success Factors of Knowledge Management (KM) Implementations in Singapore,' Singapore, Bawany Associates Pte Ltd.

Benbya, H., Passiante, G. \& Belbaly, N. A. (2004)."Corporate Portal: A Tool for Knowledge Management Synchronization," International Journal of Information Management, 24, 201-220.

Bharadwaj, A. S. (2000)."A Resource-Based Perspective on Information Technology Capability and Firm Performance: An Empirical Investigation," MIS Quarterly, 24, 169-96.

Bhatt, G., Emdad, A., Roberts, N. \& Grover, V. (2010). "Building and Leveraging Information in Dynamic Environments: The Role of IT Infrastructure Flexibility as Enabler of Organizational Responsiveness and Competitive Advantage,"Information \& Management, 47, 341-349.

Blake, P. (1998). 'The Knowledge Management Expansion,' Information Today, $15,12-13$.

Bloodgood, J. M. \& Salisbury, W. D. (2001). "Understanding the Influence of Organizational Change Strategies on Information Technology and Knowledge Management Strategies," Decision Support Systems, 31, 55-69. 
Burca, S. D., Fynes, B. \& Brannick, T. (2006). "The Moderating Effects of Information Technology Sophistication on Services Practice and Performance," International Journal of Operations \& Production Management 26, 1240-1254.

Chong, S. C. (2005). "Implementation of Knowledge Management among Malaysian ICT Companies: An Empirical Study of Success Factors and Organisational Performance," Faculty of Business and Law. Multimedia University, Malaysia.

Chong, S. C. \& Choi, Y. S. (2005). 'Critical Factors in the Successful Implementation of Knowledge Management,' Journal of Knowledge Management Practice.

Christopher, H.-J. (2006). "Knowledge Management Past and Future," KM World, 15, 20.

Cooper, D. R. \& Schindler, P. S. (2006). Business Research Methods, McGraw Hill.

Debowski, S. (2006). Knowledge Management, Wiley.

Galbraith, J. R. (1974)."Organization Design: An Information Processing View," Interfaces, 4, 28-36.

Hahn, J. \& Subramani, M. R. (2000). "A Framework of Knowledge Management Systems: Issues and Challenging for Theory and Practice," International Conference on Information Systems, Brisbane, Queensland, Australia, Association for Information Systems.

Hair, J. F. J., Black, W. C., Babin, B. J. \& Anderson, R. E. (2010). 'Multivariate Data Analysis - A Global Perspective,' New Jersey, Pearson Prentice Hall.

Holsapple, C. W. \& Joshi, K. D. (2002a). "Knowledge Management: A Threefold Framework," Information Society, 18, 47-64.

Holsapple, C. W. \& Joshi, K. D. (2002b). "Knowledge Manipulation Activities: Results of a Delphi Study," Information \& Management, 39, 477-490.

Kim, S.-K. (2001). "An Empirical Study of the Relationship between Knowledge Management and Information Technology Infrastructure Capability in the Management Consulting Industry," Nebraska, The University of Nebraska, Lincoln.

Kline, R. B. (2005). Principles and Practice of Structural Equation Modeling, The Guilford Press.

Kline, R. B. (2009). Becoming A Behavioral Science Researcher, The Guilford Press.

MDeC (2008). [Online]. [Retrieved January 15, 2008], http://www.msc.com.my

MDeC (2010a). [Online]. [Retrieved December 17, 2010], http://www.msc.com.my

MDeC (2010b). "Services Statistics : Information and Communications Technology, 2008"[Online]. [Retrieved February 17, 2010], http://www.statistics.gov.my/portal/images /stories/files/LatestReleases/findings/02IC T_2009_Summary_of_findings.pdf

Meek, T. (1999). "The Evolution of Information Technology at Buckman: How an IT Infrastructure can Support Knowledge Management," Knowledge Management Review, November/December 1999.

Mergawati, Z. (2006). "Don't Lose your Staying Power, PM Advises MSC Malaysia," The Star Newspaper, Cyberjaya.

Meso, P. \& Smith, R. (2000). "A Resourcebased View of Organizational Knowledge Management Systems," Journal of Knowledge Management, 4, 224-234.

Nath, V. (2000)." Heralding ICT Enabled Knowledge Societies: Way for Forwarding for the Developing Countries," 
Ngai, E. W. T. \& Chan, E. W. C. (2005). "Evaluation of Knowledge Management Tools Using AHP," Expert Systems with Applications, 29, 889-899.

Nonaka, I. (1994). "A Dynamic Theory of Organizational Knowledge Creation," Organization Science, 5, 14-37.

Premkumar, G., Ramamurthy, K. \& Saunders, C. S. (2005). "Information Processing View of Organizations: An Exploratory Examination of Fit in the Context of Interorganizational Relationships," Journal of Management Information Systems, 22, 257-294.

Qi, X., Lan, B. \& Guo, Z. (2008)."Conceptual Model of IT Infrastructure Capability and Its Empirical Justification," Tsinghua Science \& Technology, 13, 390-394.

Sabherwal, R. Sabherwal, S. (2005). "Knowledge Management Using Information Technology: Determinants of Short-Term Impact on Firm Value," Decision Sciences, 36, 531-567.

Schwager, P. H., Byrd, T. A. \& Turner, D. E. (2000). 'Information Technology Infrastructure Capability's Impact on Firm Financial Performance: An Exploratory Study,' The Journal of Computer Information Systems, 40, 98-104.

Sher, P. J. \& Lee, V. C. (2004). "Information Technology as a Facilitator for Enhancing Dynamic Capabilities through Knowledge Management," Information \& Management, 41, 933-945.

Sidhu, J. S. (2006). "Information and Communications Technology among Key Focus of 9MP," The Star Online. Kuala Lumpur.

Taap, M. A. (2001). 'Challenges and Potentials in Human Resource Development in a Knowledge-based Economy: A Malaysian Perspective,'

Tallon, P. P. (2008). "Inside the Adaptive Enterprise: An Information Technology
Capabilities Perspective on Business Process Agility," Information Technology and Management, 9, 21-36.

Tanriverdi, H. (2001). 'Performance Effects of Corporate Diversification: Roles of Knowledge Resources, Knowledge Management Capability and Information Technology,' Massachusetts, Boston University.

Tiwana, A. (2000). "The Knowledge Management Toolkit: Practical Techniques for Building a Knowledge Management System," Prentice-Hall, Inc.

Tiwana, A. (2002). The Knowledge Management Toolkit: Orchestrating IT, Strategy, and Knowledge Platforms, Prentice Hall PTR.

Tuttle, D. B., Hart, A. L., Collier, W. A., Janssen, D., van Heijst, G., van der Spek, R. \& Kruizinga, E .(1997)."Corporate Memories as a Tool for knowledge Management," Expert Systems with Applications, 13, 41-54.

Wade, M. \& Hulland, J. (2004). "Review: The Resource-based View and Information Systems Research: Review, Extension, and Suggestions for Future Research," MIS Quarterly, 28, 107-142.

Wang, E., Klein, G. \& Jiang, J. J. (2007). "IT Support in Manufacturing Firms for a Knowledge Management Dynamic Capability Link to Performance," International Journal of Production Research, 45, 2419-2434.

Weil, P. \& Broadbent, M. (1998). Leveraging The New Infrastructure: How Market Leaders Capitalize On Information Technology, Boston, Massachusetts, Harvard Business School Pres.

Weill, P. (1992). "The Relationship between Investment in Information Systems and Firm Performance: A Study of the Valve Manufacturing Sector," Information Systems Research, 3, 307-333. 
Zack, M. H. (1999a). "Developing a Knowledge Strategy," California Management Review, Spring99, 41, 21 (125-145).
Zack, M. H. (1999b). "Managing Codified Knowledge," Sloan Management Review, 4558.

Appendix A: List of Items Used

\begin{tabular}{|c|c|c|c|}
\hline Item & Description & Scale Type & Variable \\
\hline D1 & $\begin{array}{l}\text { Perform flexibility in unpredictable } \\
\text { environment. }\end{array}$ & \multirow[t]{14}{*}{ 5-point Likert } & \multirow{14}{*}{$\begin{array}{l}\text { Information } \\
\text { Infrastructure } \\
\text { Capability (IIC) } \\
\text { Dynamic (D) } \\
\text { Integrating (I) } \\
\text { Data } \\
\text { Management } \\
(D M) \\
\text { Security (S) } \\
\text { Utility (U) } \\
\text { Collaboration }(C)\end{array}$} \\
\hline $\mathrm{D} 2$ & $\begin{array}{l}\text { Perform responsiveness in unpredictable } \\
\text { environment. }\end{array}$ & & \\
\hline D3 & $\begin{array}{l}\text { Perform better competitiveness among } \\
\text { rivals. }\end{array}$ & & \\
\hline $\mathrm{I} 1$ & $\begin{array}{l}\text { Recommend standard for at least one } \\
\text { component of IT architecture (i.e., } \\
\text { hardware, OS, data, communications). }\end{array}$ & & \\
\hline $\mathrm{I} 2$ & Enforcing IT architecture. & & \\
\hline I3 & $\begin{array}{l}\text { Provide data sources in a unified view } \\
\text { within an organisation. }\end{array}$ & & \\
\hline DM1 & $\begin{array}{l}\text { Manage communication network within } \\
\text { an organisation. }\end{array}$ & & \\
\hline DM2 & $\begin{array}{l}\text { Manage messaging services within an } \\
\text { organisation. }\end{array}$ & & \\
\hline DM3 & $\begin{array}{l}\text { Manage workstation networks within an } \\
\text { organisation. }\end{array}$ & & \\
\hline DM4 & $\begin{array}{l}\text { Manage business unit application within } \\
\text { an organisation. }\end{array}$ & & \\
\hline DM5 & $\begin{array}{l}\text { Manage business unit data including } \\
\text { standards within an organisation. }\end{array}$ & & \\
\hline DM6 & Manage database within an organisation. & & \\
\hline DM7 & $\begin{array}{l}\text { Manage, maintain, and support large- } \\
\text { scale data processing facilities. }\end{array}$ & & \\
\hline DM8 & $\begin{array}{l}\text { Provide data management advice and } \\
\text { consultancy services. }\end{array}$ & & \\
\hline
\end{tabular}


Appendix A: List of Items Used (Continued)

\begin{tabular}{|c|c|c|c|}
\hline Item & Description & Scale Type & Variable \\
\hline S1 & $\begin{array}{l}\text { Provide security for installation and } \\
\text { application within an organisation. }\end{array}$ & \multirow[t]{2}{*}{ 5-point Likert } & \multirow[t]{2}{*}{ IIC } \\
\hline S2 & $\begin{array}{l}\text { Implement disaster planning and recovery } \\
\text { for business units. }\end{array}$ & & \\
\hline S3 & $\begin{array}{l}\text { Implement regular backup for files and } \\
\text { document. }\end{array}$ & & \\
\hline $\mathrm{U} 2$ & $\begin{array}{l}\text { Provide technology education services } \\
\text { (training). }\end{array}$ & & \\
\hline U3 & $\begin{array}{l}\text { Perform information system (IS) project } \\
\text { management. }\end{array}$ & & \\
\hline $\mathrm{U} 4$ & Perform IS planning for business units. & & \\
\hline U5 & $\begin{array}{l}\text { Identify and test new technologies for } \\
\text { business purposes. }\end{array}$ & & \\
\hline U6 & $\begin{array}{l}\text { Manage and negotiate with suppliers and } \\
\text { outsourcers. }\end{array}$ & & \\
\hline $\mathrm{C} 1$ & $\begin{array}{l}\text { Provide multimedia operations and } \\
\text { development (i.e., video conferencing) }\end{array}$ & & \\
\hline $\mathrm{C} 2$ & $\begin{array}{l}\text { Provide intranet for document } \\
\text { management. }\end{array}$ & & \\
\hline C3 & Provide intranet for collaboration. & & \\
\hline $\mathrm{C} 4$ & $\begin{array}{l}\text { Provide electronic support for members of } \\
\text { other work groups within an organisation. }\end{array}$ & & \\
\hline $\mathrm{C} 5$ & $\begin{array}{l}\text { Develop a common system development } \\
\text { environment. }\end{array}$ & & \\
\hline CA1 & Stimulation and motivation of employees. & 5-point Likert & $\begin{array}{l}\text { Competitive } \\
\text { Advantage (CA) }\end{array}$ \\
\hline CA2 & $\begin{array}{l}\text { Formalised knowledge transfer system } \\
\text { (Best practices, lessons learned). }\end{array}$ & & \\
\hline CA3 & Better on-the-job training for employees. & & \\
\hline CA4 & $\begin{array}{l}\text { Enhanced enterprise innovation and } \\
\text { creativity. }\end{array}$ & & \\
\hline CA5 & Improved overall enterprise performance. & & \\
\hline
\end{tabular}


Appendix A: List of Items Used (Continued)

\begin{tabular}{|c|c|c|c|}
\hline Item & Description & Scale Type & Variable \\
\hline CA6 & $\begin{array}{l}\text { Enhanced client relations - better client } \\
\text { interaction. }\end{array}$ & 5-point Likert & $\begin{array}{l}\text { Competitive } \\
\text { Advantage (CA) }\end{array}$ \\
\hline CA7 & $\begin{array}{l}\text { Development of an entrepreneurial } \\
\text { culture for enterprise growth and } \\
\text { success. }\end{array}$ & & \\
\hline CA8 & Improved employee retention. & & \\
\hline CA9 & $\begin{array}{l}\text { Improved ability to sustain a } \\
\text { competitive advantage. }\end{array}$ & & \\
\hline CA10 & $\begin{array}{l}\text { Enhanced transfer of knowledge from } \\
\text { one employee to another. }\end{array}$ & & \\
\hline CA11 & $\begin{array}{l}\text { Means to identify industry best } \\
\text { practices. }\end{array}$ & & \\
\hline CA12 & $\begin{array}{l}\text { Better methods for enterprise-wide } \\
\text { problem solving. }\end{array}$ & & \\
\hline CA13 & $\begin{array}{l}\text { Enhanced business development and } \\
\text { the creation of enterprise opportunities. }\end{array}$ & & \\
\hline CA14 & $\begin{array}{l}\text { Enhanced and streamlined internal } \\
\text { administrative processes. }\end{array}$ & & \\
\hline CA15 & Improved responsiveness and flexibility. & & \\
\hline CA16 & Improved products/services quality. & & \\
\hline CA17 & $\begin{array}{l}\text { Improved product development life } \\
\text { cycle. }\end{array}$ & & \\
\hline CA18 & Expedite the decision making process. & & \\
\hline
\end{tabular}

